\title{
FOOD WARMER SYSTEM BASED ON DHT-22
}

\author{
Asti Riani Putri \\ Prodi Pendidikan Teknologi Informasi \\ STKIP PGRI Tulungagung \\ Tulungagung \\ Jawa Timur,Indonesia \\ asti@stkippgritulungagung.ac.id
}

Abstract- A warm meal will make those who eat it feel comfortable, especially those who have a history of suffering from gastritis or respiratory problems such as asthma from the incident means that they need a portable food warmer that can warm food wherever and whenever. So the purpose of this research is to create a temperature control and monitoring system automatically using a DHT22 sensor as a temperature gauge and fan, and incandescent lamps as a stabilizer of its temperature. The method used in the temperature regulation system using fuzzy logic. Fuzzy logic is a method of control system that can provide decisions that resemble humans. By determining the membership and fuzzy logic rules in the microcontroller as the brain, the temperature can be adjusted automatically.

The result is making a food warmer that can maintain heat stability from food and can be taken anywhere.

Keywords : DHT22, Temperature, Fuzzy Logic

\section{INTRODUCTION}

The development of technology and science is currently growing rapidly. This is done aiming to simplify everyday human work. Creating tools that had never before existed until the development of existing tools in order to perfect their functions and benefits. The development of technology and science have influenced various aspects of daily life.

As well as the need for equipment that is supported by technology is also very necessary because it can help and facilitate human beings in carrying out their duties or alleviate human burdens. This technology will involve a microcontroller, sensors and artificial intelligence.

Several studies [1] have developed incubators, so that the temperature is maintained automatically using a microcontroller. Microcontroller is as a computer system that is built on a single chip (chip). Microcontroller is a processor used for control purposes. In this study, Arduino uno microcontroller which is a microcontroller board that is fully controlled by ATmega328 [2] and is assisted by a fuzzy logic control system as a data processing input is obtained from the DHT22 temperature sensor which in turn produces the output that we expect, namely the temperature in the food warmer is automatically maintained properly. Therefore researchers will develop research entitled "DHT22-based portable food warmer systems".

\author{
Putri Nur Rahayu \\ Prodi Teknologi Informasi \\ Universitas Islam Kediri \\ Kediri \\ Jawa Timur,Indonesia \\ Putri_nur_rahayu@yahoo.co.id
}

\section{A. Arduino Uno Microncontroller}

II. BASIC THEORY

Arduinois one of the microcontroller education products as an open licensed pilot project and is able to function as a final product [3]. The main component of the tool made is Arduino Uno. Arduino functions as the brain of every movement made by the system to be made. Arduino will process all incoming input, and will output according to the program that has been uploaded into it.

Arduinois an open source electronic circuit board in which there are main components namely, a microcontroller chip. Arduino UNO is a microcontroller board that is fully controlled by ATmega328 (Suryowinoto, Hamid, \& Lelono, 2016). As shown in Figure 2.1 below, Arduino UNO has 14 digital input or output pins (6 of which can be used as PWM outputs), 6 analog inputs, a $16 \mathrm{MHz}$ Crystal oscillator, a USB connection, a power jack, an ICSP header, and a reset button. Arduino UNO contains everything needed to support a microcontroller, easily connect it to a computer with a USB cable or supply it with an AC to DC adapter or use a battery to get started [4].

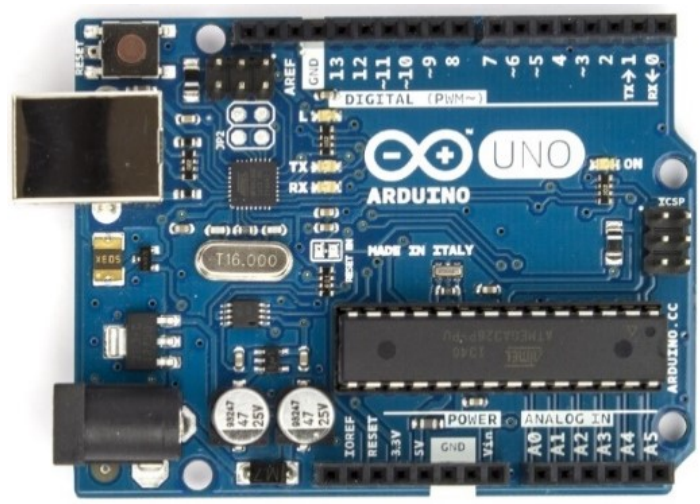

Figure 2.1 Arduino Uno [5]

Arduino Uno board specifications that have been simplified as shown in Figure 2.1 Shield is a board that can be mounted on the Arduino board to increase the capability of the Arduino board. The programming language used in Arduino is not a relatively difficult assembler language, but rather a programming language similar to the $\mathrm{C}$ programming language which is simplified with the help of the Arduino libraries. Here is an explanation of the Arduino microcontroller board:

Table 2.1 Arduino Uno Board Specifications 
Source: [6]

\section{B. Fuzzy Logic}

Logic fuzzyfirst introduced in 1965 by Prof. Lutfi A. Zadeh, a researcher at the University of California at Barkley in the field of computer science (Division \& Sciences, 1978). Professor Zadeh assumed that logic of

\begin{tabular}{|c|c|c|}
\hline NO & Spesification & Information \\
\hline 1 & Microcontroller & ATmega328 \\
\hline 2 & Operating Voltage & $5 \mathrm{~V}$ \\
\hline 3 & $\begin{array}{l}\text { input voltage } \\
\text { (recommended) }\end{array}$ & $7-12 \mathrm{~V}$ \\
\hline 4 & $\begin{array}{l}\text { input voltage } \\
\text { (limit) }\end{array}$ & $6-20 \mathrm{~V}$ \\
\hline 5 & Digital I / O Pin & $\begin{array}{c}14 \text { (6 including } P_{\text {V } \mathbf{~ v ı ~}} \\
\text { pins) }\end{array}$ \\
\hline 6 & Analog Input Pin & 6 input pin 21 \\
\hline 7 & $\begin{array}{c}\text { DC Current Per } \\
\text { Pin } I / O\end{array}$ & $40 \mathrm{~mA}$ \\
\hline 8 & $\begin{array}{c}\text { DC current for Pin } \\
3,3 \mathrm{~V}\end{array}$ & $150 \mathrm{~mA}$ \\
\hline 9 & Flash memory & $\begin{array}{c}32 \mathrm{~KB} \text { and } 0.5 \mathrm{~KB} \text { used } \\
\text { bootloader }\end{array}$ \\
\hline 10 & SRAM & $2 \mathrm{~KB}$ \\
\hline 11 & EEPROM & $1 \mathrm{~KB}$ \\
\hline 12 & Clock Speed & $16 \mathrm{Mhz}$ \\
\hline
\end{tabular}

right and wrong could not represent every human thought, then fuzzy logic was developed which could represent every state or represent human thought. The difference between strict logic and fuzzy logic lies in the membership of elements in a set. If in strict logic an element has two choices which are contained in the set or value 1 which means true and not on the set or value 0 which means false. Whereas in fuzzy logic, element membership is in the interval [6] $(0,1)$

(various systems that exist in decision making because fuzzy logic has the following advantages:

1. Fuzzy logic has a very simple concept that is easy to understand.

2. Fuzzy logic is very flexible, meaning that it is able to adapt to changes and uncertainties.

3. Fuzzy logic has a tolerance for incorrect data.

4. Fuzzy logic is able to systemate non-linear functions that are very complex.

5. Fuzzy logic can apply experience or knowledge from experts.

6. Fuzzy logic can work with conventional control techniques.

7. Fuzzy logic is based on everyday language so it's easy to understand.

On fuzzylogic to build a system that uses fuzzy rules, the processes that need to be used are fuzzyfication, inference and finally defuzzyfication.

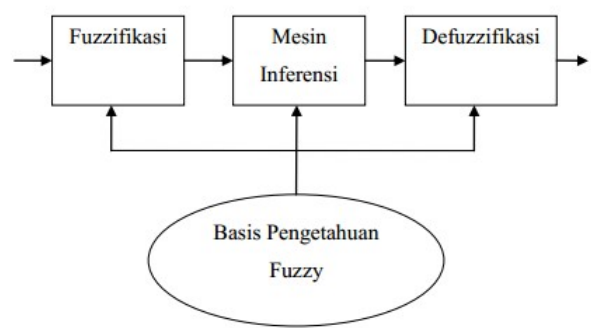

Figure. 2.2 Structure of a Fuzzy Inference System

\section{Fuzzification}

Fuzzificationis the first step in the fuzzy method which is tasked with taking the input value in the form of a crisp value (crisp), and determining the degree of input so that the input can be grouped in the right fuzzy set. Fuzzification is the process of making crispy numbers have fuzzy values. In this first stage, input values in the form of crisp values will be converted into fuzzy values, so that they can be grouped in certain fuzzy sets (Budiharto \& Suhartono, 2014). It can be said that fuzzification is a process to change non-fuzzy variables (variables 57 inguis) becomes a fuzzy variable (variable 57inguistic).

\section{Inference}

The second step is to take the input values that have been fuzzified and apply them to the antecedents of the fuzzy rules and then to be implied (Budiharto \& Suhartono, 2014). In general, inferences are fuzzy rules expressed in the form of "IF ... THEN" which is the core of fuzzy relations.

The following will explain the types of inference fuzzy The Mamdani, Tsukamoto and Sugeno methods are often used in various studies.

a. Mamdani Method

The Mamdani method was first introduced by Ibrahim Mamdani in 1975. This method is the simplest and most frequently used method for research compared to other methods. Input and output in the method of fuzzy set. The method of mam and using the function of the implication of min and max aggregation so that the mamdani method is also called the MIN-MAX method ( $\min \max$ inferencing). The output for the mamdani method rules are defined as follows.

$\mu \mathrm{Bk}(\mathrm{y})=\max [\min [\mu \mathrm{Ak} 1$ (xi), $\mu \mathrm{Ak} 1$ (xi)] $\mathrm{k} \ldots$ (1)

for $\mathrm{k}=1,2, \ldots, \mathrm{n}, \mathrm{Ak} 1$ and $\mathrm{Ak} 2$ represent the fuzzy set of the kth antecedent pair, and $\mathrm{Bk}$ is the consequent fuzzy set. (Sri and Hari, 2013).

b. Tsukamoto Method

Method Tsukamoto is a method where the consequence of the fuzzy rules is represented by a monotonous membership function.

c. Sugeno Method

Unlike the Mamdani method, the Sugeno method also uses the fuzzy set on the input. However, the output used in the Sugeno method is a constant or a linear equation. This method was first introduced by Takagi Sugeno Kang in 1985 (Hidayati, Aisuwarya, \& Putri, 2017). If in the mamdani method the 
JAREE-Journal on Advance Research in Electrical Engineering Volume4, Number 1, April 2020

defuzzification process uses curve area aggregation, then the sugeno aggregation method is singletonsingleton.

\section{Defuzzification}

The final step of the process defuzificationis to convert fuzzy values resulting from the aggregation of rules into a crispy number (Budiharto \& Suhartono, 2014). Methods in defuzzification include:

a) The centroid method is also called the center of grafity method or the Center of Area (CoA) method. The defuzzification process in the centroid method is to take the central point value () from the region in the membership function. The centroid method formula is defined as:

$$
X *=\frac{f_{x} x \mu B(x) d x}{f_{x} x p B(x) d x} .
$$

for continuous domains, and

$$
X *=\frac{\sum_{i}^{n}=1 \text { xi } \mu B(x i)}{\sum_{i}^{n}=1 \text { xipR }(x i)}
$$

for discrete domains.

Besides being easy in calculation, the advantages of using the method centroid is a defuzzy value moves smoothly so that the change from a fuzzy set topology to the next fuzzy set topology also moves smoothly.

b) Bisector Method

The bisector method takes values in the nfuzzy set domain that have membership values in the fuzzy region as a firm solution, and is defined as:

$$
\begin{aligned}
& X p \\
= & \int_{a}^{p} \mu(x) d x=\int_{p}^{b} \mu(x) d x .
\end{aligned}
$$

(4)

With $\quad a=\min (x: x \in X) \quad$ dan $\quad \mathrm{b}=\max (x: x \in X)$

Whereas $\mathrm{p}=\mathrm{x}$ which divides the area of inference into two equal parts.

c) Mean of Maximum (MOM) Method

A resolute solution is obtained by taking the average value of a domain that has a maximum membership value.

d) Largest of Maximum (LOM) Method

A resolute solution is obtained by taking the greatest value from a domain that has a maximum membership value.

e) The Smallest of Maximum (SOM) Method

The firm solution is obtained by taking the smallest value from domain which has the maximum membership value.

\section{Fuzzy System Testing}

At this stage, data analysis is in the design incubator based on fuzzy logic is to get a good temperature sensor accuracy and can control the temperature in accordance with the desired temperature.

Observation data taken from each test is used to determine the appropriateness of the tools that have been made. Data analysis onfuzzy logic incubatorThis is done by finding the suitability of the parameters at the set point (SP) and the temperature detected by the temperature sensor. With the following formula: Percentage of deviation

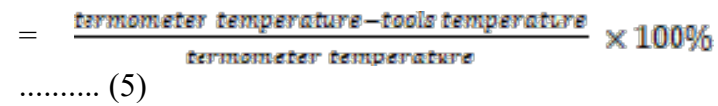

Error in the system is based on input data. The magnitude of the error can be identified by:

Accuracy $=100 \%$ - average percentage deviation

(A. Hidayat, 2017)

\section{DHT22 Temperature Sensor}

DHT-22or AM2302 is a temperature and humidity sensor, this sensor has an output in the form of a digital signal with conversions and calculations carried out by an integrated 8-bit MCU. This sensor has an accurate calibration by adjusting the room temperature compensation with the coefficient value stored in the integrated OTP memory. The DHT22 sensor has a wide temperature and humidity measurement range, DHT22 is able to transmit the output signal through the cable up to 2 meters so it is suitable to be placed anywhere, but if the cable is longer than 2 meters a $0.33 \mu \mathrm{F}$ buffer capacitor must be added between pins \# 1 ( VCC) with pin \# 4 (GND).

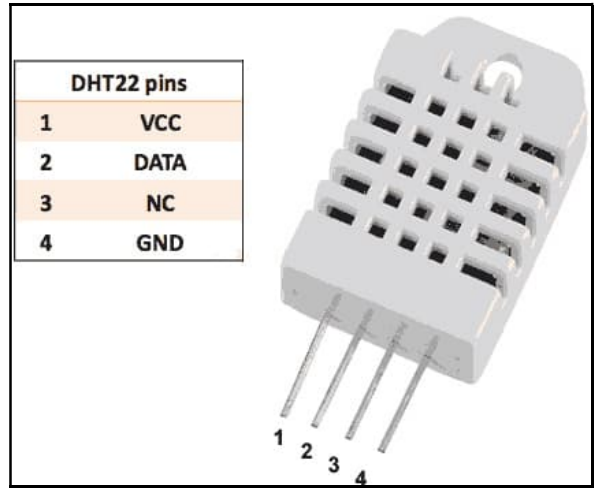

Figure 2.3 DHT22 Temperature Sensor

DHT22 / AM-2302 Technical Specifications:

1. Power supply: 3.3 - 6 Volt DC (typical 5 VDC)

2. Output signal: digital via a single bus with speed

3. $5 \mathrm{~ms} /$ operation

4. Detecting element: polymer capacitor

5. Sensor type: capacitive (capacitive sensing)

6. Humidity detection range: $0-100 \%$ RH (accuracy \pm $2 \% \mathrm{RH})$

7. Temperature detection range: $-40^{\circ}-+80^{\circ}$ Celsius (accuracy $\pm 0.5^{\circ} \mathrm{C}$ )

8. Sensitivity resolution: $0.1 \% \mathrm{RH} ; 0.1^{\circ} \mathrm{C}$

9. Hysteresis humidity: $\pm 0.3 \% \mathrm{RH}$

10. Long term stability: $\pm 0.5 \% \mathrm{RH} /$ year

11. Average scan period: 2 seconds

12. Size: $25.1 \times 15.1 \times 7.7 \mathrm{~mm}$

13. Connect pin \# 2 (data) of this sensor to the Digital I / Opada MCU (Microcontroller Unit) pin.

Communication and signal A single data bus is used for communication between MCU and DHT22, with a time of $5 \mathrm{~ms}$ for one time communication. Data consists of integral and decimal parts, the following is the formula for the data. 
DATA $=16$ bits RH data +16 bits Temperature data + 8 bits check-sum MCU has received 40 bits of data from AM2302:

0000001010001100000000010101111111101110

16bit data RH 16bit data $\mathrm{T}$ 8bit Number of checks here changing 16 bits of RH data from the binary system to the decimal system,

$0000001010001100 \rightarrow 652$

System binary decimal system

$R H=652 / 10=65.2 \% \mathrm{RH}$, here the conversion of 16 data bits $\mathrm{T}$ from the binary system to the decimal system,

$0000000101011111 \rightarrow 351$

Binary system

Decimal System

$T=351 / 10=35.1^{\circ} \mathrm{C}$

Sum $=00000010+10001100+00000001+0101$

$1111=11101110$

Check-sum $=$ The last 8 bits of Sum $=111011102$

\section{DC fan}

Fan $D C$ is an electronic device that serves to produce wind with a voltage source used is $12 \mathrm{~V}$. The advantage of this device is to have a practical shape so it is very suitable to be placed on another device to facilitate air circulation, besides this DC fan does not produce a noisy sound on the movement of the fan (Hidayat) \& Rusimanto, 2019).

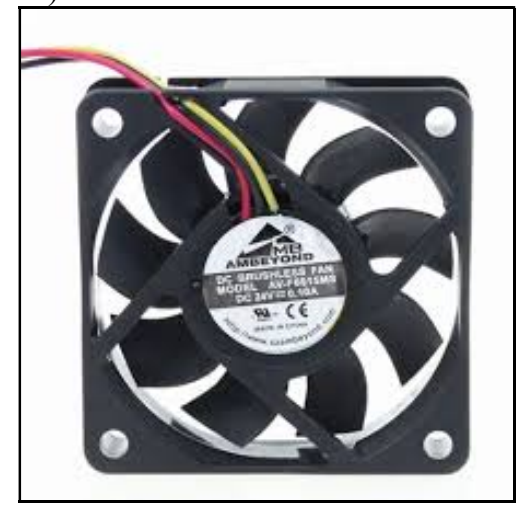

Figure 2.4 DC fan

\section{E. Incandescent lamps}

An incandescent lamp is a device that produces light by heating a filament wire to high temperatures and creating light. The light bulb is supplied with an electric current withfeedthrough terminals or wires attached to glass. Incandescent lamps are manufactured with various voltage sizes ranging from $1.5 \mathrm{~V}$ to $300 \mathrm{~V}$. Incandescent lamps are widely used because they have cheap and efficient prices because they do not require other external equipment.

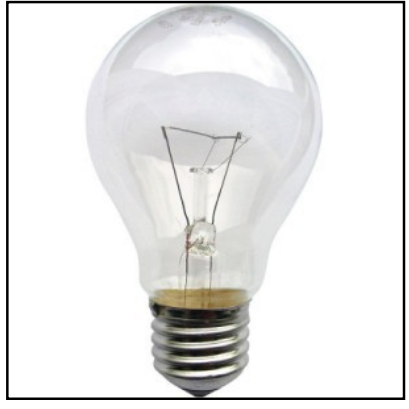

Figure 2.5 Incandescent Bulbs

\section{F. Power Supply}

Electronic devices should be supplied by direct current / DC (direct current)which is stable so that it can work well. Batteries or batteries are the best source of DC power supply. One of the voltage requirements that are used to supply power to an instrument system is that the voltage is a stable direct current (DC) voltage. That is because the electronic component of building a tool (Robot) is a component that works in direct current (DC) with a stable voltage. The meaning of stability is that the voltage does not fluctuate (ripple) to the extreme, which can cause the electronic components of the system builder to not work properly, or even become damaged. In other words, if the robot system uses a voltage power supply of 12 volts $\mathrm{dc}$, then the voltage entered into the electronics system must be exactly 12 volts, not 12.6 volts or 11.9 volts (Istiyanto,

\section{G. Drive Motor L298 (Motor Driver)}

Motor movers are divided into two categories, namely the direction of rotation $D C M P$ (Permanent magnet DC) and the main component categories making up the DCMP drive circuit. Drivers in the DCMP rotation direction category are DCMP drives that rotate clockwise $(\mathrm{CW})$ and DCMP drives that rotate counter-clockwise (CCW). While the movers in the main category of DCMP drive circuit compilers are DCMP drives that use transistor components and DCMP drives that use integrated circuits (IC).

Module L298n motor driveris a DCMP driver that uses integrated circuit IC L298. Based on the data-sheet, ICL298 can work with supply voltages up to 46 volts DC and has a maximum working current (DC) of up to 4 amperes. With these specifications, IC L298 can be used in controlling DCMP motor rotation with a working current of up to 4 Amperes. IC L298 has 15 legs which has its own function.

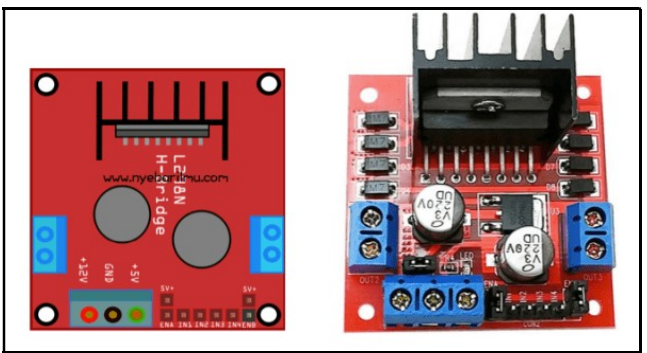

Figure 2.6 L298N Motorcycle Driver Module 


\section{H. Relay}

Relay is a switch that is controlled by current. The relay has a low-voltage coil wrapped around a core. There is an iron armature that will be attracted to the core if current flows through the coil. This armature is mounted on a spring-loaded lever. When the armature is drawn towards this, the joint contact path will change its position from normal-closed contact to normal-open contact (Turang, 2015).

Relay is a switch (Switch) that is operated electrically and is a component Electromechanical (Electromechanical) which consists of 2 main parts namely Electromagnet (Coil) and Mechanical (a set of Contact Switch / Switch) (Kho, 2013).

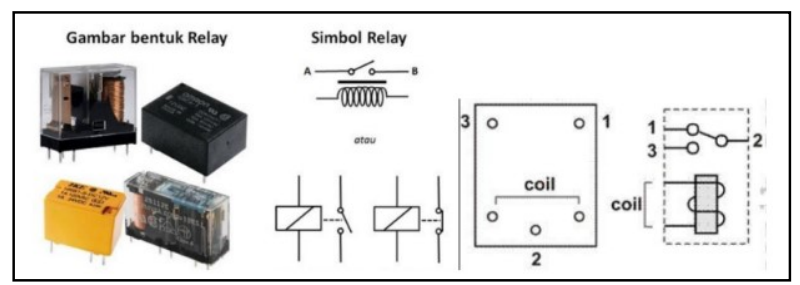

Figure 2.7 Physical Form of Relay

Relays can be used to control the motor air conditioningwith DC control circuits or other loads with different voltage sources between the control circuit voltage and the load voltage. Relay drive circuit can be seen in Figure 2.3 Among the relay applications that can be found include: Relay as control ON / OF loads with different tension sources. Relay as a selector or relationship selector. Relay as executor of the circuit delay (delay) relay as a protector or a circuit breaker under certain conditions. Relay properties:

1. The coil impedance, usually the impedance is determined by the thickness of the wire used and the number of turns. Usually the impedance is 1 $50 \mathrm{~K} \Omega$ in order to obtain good conductivity.

2. The power needed to operate a relay is the same as the voltage value times the current.

3. The number of anchor contacts can open and close more than one contact at a time depending on the contact and relay type. The distance between contacts determines the maximum allowable voltage between the contacts.

\section{RESEARCH METHODS}

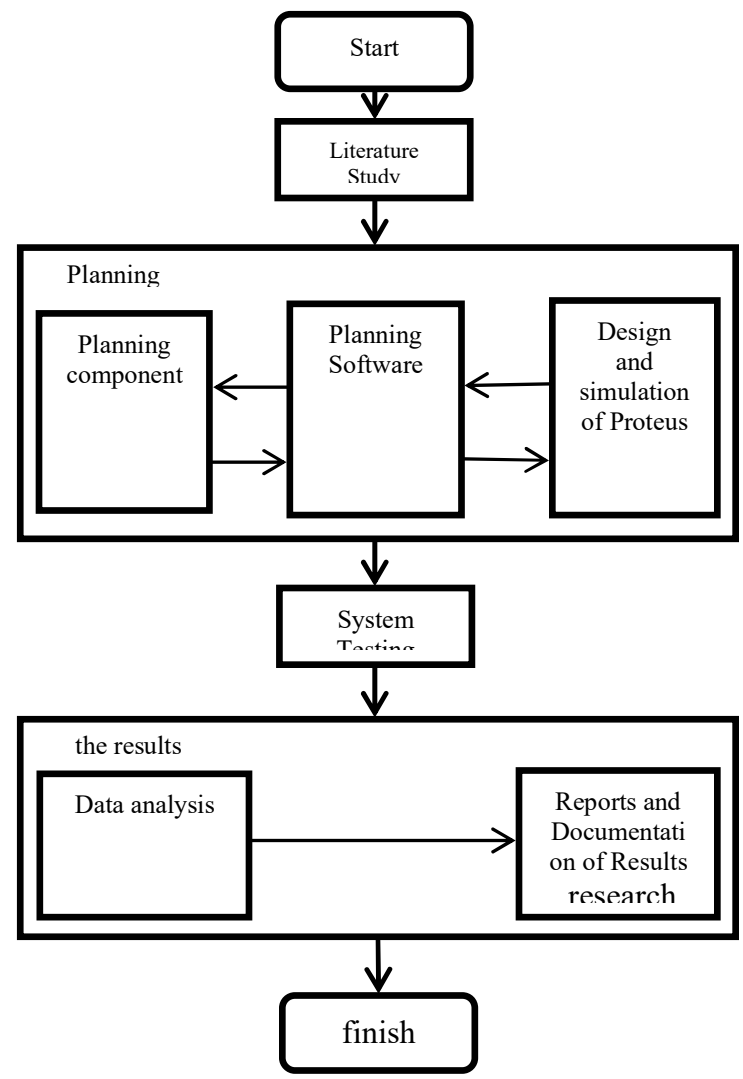

Figure 3.1 above is the flow of research that will be carried out in implementing the development of temperature control and monitoring systems in the incubator room. The following describes each step in the research:

\section{Study of literature}

At this stage observations and literature studies are carried out in order to obtain information that is used as initial data for the basis of determining the needs of system design and components to conduct simulations and then research. The collection of initial information regarding:

a) Arduino Language programming tutorial

b) Temperature and humidity sensor module DHT22

c) Integrated Electronics

d) PWM (Pulse Width Modulation)

\section{Design}

The next stage after conducting a literature study is the longest stage in the research flow. This stage includes simulations using proteus software, software design (compilation of source code) and component design. Each of the steps in the design stage will be interconnected, so that if there is a failure the researcher can return to the previous step. Here is a description of each step in the design stage, namely:

\section{a. Design and Simulation}

The simulation phase is carried out using the proteus application as a support in gathering the main data of the components and the placement of pin cables that will be needed in the development of this system. From the 
simulation results will be used as a reference in the form of components that will be used and the program in developing the temperature control and monitoring system in the incubator. For more details can be seen in Figure 3.2 below:

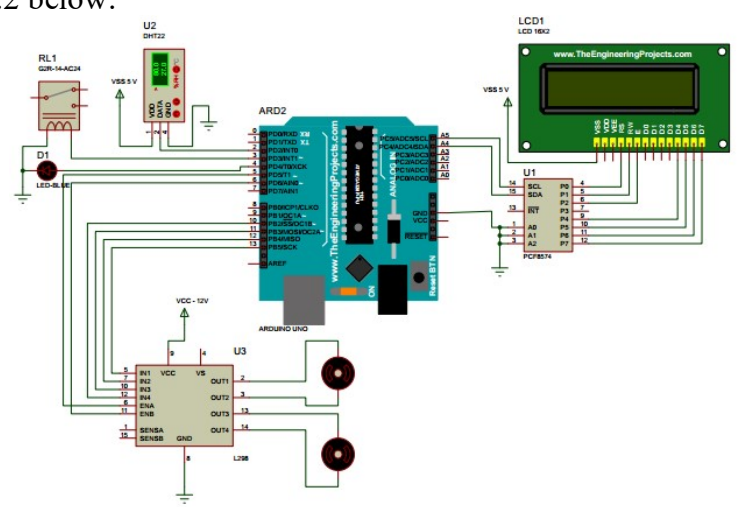

Figure 3.2 Design and Simulation with Proteus Applications

\section{b. Software Design}

Software design in temperature control and monitoring system in the incubator room starts from the process of reading the temperature and controlling temperature stability using the fuzzy logic method. The program flowchart that will be created can be seen inFigure 3.3

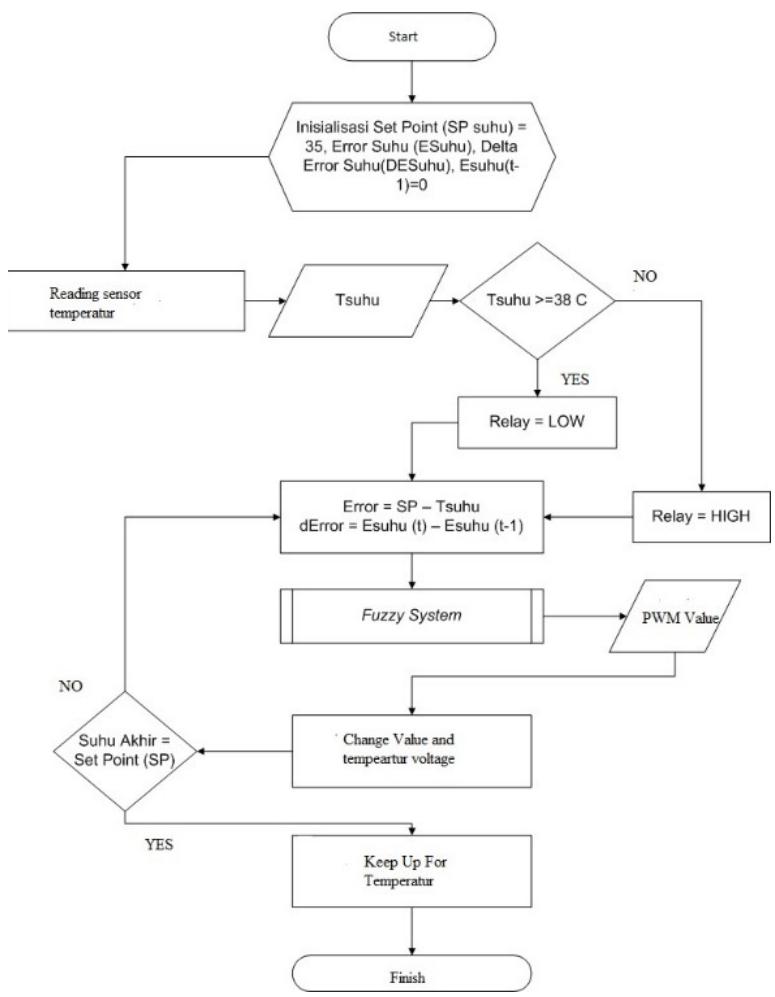

Figure 3.3 Flowchart Main Program

In the initial stage, several variables will be initialized, namely set point temperature (SP Temperature), Error temperature and Delta Error temperature (error). After the variable has been initialized the temperature reading by the sensor can be done. The read temperature will be used to obtain the Error and Temperature Error values. This value will be used for decision making using the fuzzy logic method. The output obtained will affect the voltage on the motor driver while affecting the temperature at that time. If the temperature obtained is the same as the set point, then the temperature will be maintained at that point, if it will not be recalculated. Flowchart fuzzy logic process as shown in Figure 3.4.

Fuzzy set and function design is done in the fuzzification stage, namely membership for Temperature Error and Temperature Error. The next step is the inferencing basis and finally defuzification. In the defuzification stage, the calculation process is carried out to determine the output (in the form of a PWM value) which will affect the voltage as well as the temperature. The process in the fuzzy algorithm will be divided into 3, namely: fuzzification, rule base inference and defuzzufication.

\section{1) Fuzzification}

The fuzzification stage is the stage of forming the fuzzification membership function divided into 2 groups, namely fuzzification error and delta error fuzzification. These two fuzzification groups are used to add parameters from the fuzzy set.

The input value (crisp) fuzzification Error comes from the difference in value from the desired set point and the temperature value displayed by the sensor. Whereas delta error fuzification input value (crisp) comes from the difference between the current error value and the previous error value. Mathematically shown in the following equation:

$$
\begin{array}{ll}
\text { Error } & =\mathrm{SP}-\text { temperature } \\
\text { Delta error } & =\mathrm{e}(\mathrm{n})-\mathrm{e}(\mathrm{n}-1) \\
\text { Information } & \text { : } \\
S P & =\text { Value Set Point } \\
\text { Temperature } & =\text { Value The output at time } \mathrm{t} \\
\mathrm{e}(\mathrm{n}) & =\text { Error value at time } t \\
\mathrm{e}(\mathrm{n}-1) & =\text { Error value at time } t-1
\end{array}
$$

Fuzzy logic inputtaken from intuition based on human instincts. In this case the error value obtained from the setpoint is subtracted from the value in the room. Generally, this study measured the temperature around $30{ }^{\circ} \mathrm{C}$ in the room so that the input error range was made from -5 to 5 based on the setpoint minus the measured temperature $(35-30=5)$.

In the fuzzification process the error and delta error values are represented using a shoulder shape curve because the left shoulder moves from right to wrong, so too the right shoulder moves from wrong to right, while the area located in the middle of a variable is represented in the form of a triangle. So that the negative variable error (EN) can be considered completely wrong when the membership value $(\mathrm{u})=1$.in figure 3.5 the value of $\mathrm{u}=1$ when the error $<=-1$ and $-1-0$ the value of the membership is determined by the triangle curve equation formula. as well as variable error zero (EZ), and positive error (EP).

\section{2) Defuzzification}

The output of the stage rule evaluationwill be used as the most correct rule and will be multiplied by the value of the degree of membership. The method used in 
JAREE-Journal on Advance Research in Electrical Engineering Volume4, Number 1, April 2020

defuzzification is Center of Gravity (COG) or centroid. Namely the sum of all the membership function outputs multiplied by the singleton of each action. The results are then averaged by the total fuzzy output.

The discrete Center of Gravity (COG) formula is as follows:

$$
\frac{\Sigma_{j}^{n}=i^{U c}\left(z_{j}\right) z j}{\Sigma_{j}^{n}=i^{U E}\left(z_{j}\right)}
$$

\section{c. Component Design}

In general, the design of temperature control and monitoring systems in lovebird cultivation incubators uses several hardware such as the DHT22 temperature sensor, $16 \times 2$ LCD, arduino uno microcontroller, DC motor fans and incandescent lamps. The working principle of the temperature control and monitoring system is a DHT22 temperature sensor measuring temperature and humidity in the lovebird incubator room, the measurement data from the temperature sensor is received by the arduino microcontroller which is then processed in the procedures that have been determined previously.

The results of the processing on the microcontroller are displayed on the $16 \times 2$ LCD screen and used as a reference to drive the DC motor fan as an effort to control the temperature. Figures 3.7 and 3.8 show the flowchart diagram of the design of a temperature control and monitoring system on a food heater.

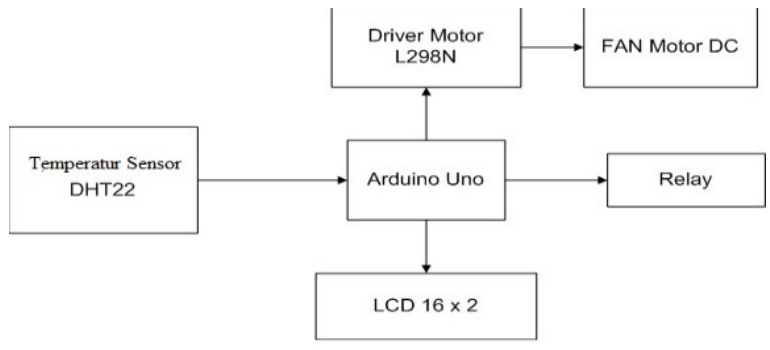

Figure 3.7 Block Diagram of Temperature Control and Monitoring System Design

\section{EXPERIMENT RESULT}

\subsection{Testing of Sensor Data for Comparators (Thermometers)}

This system stability testing aims to find out whether the system used can maintain the stability of the temperature in accordance with the set point set by setting the DC fan rotation speed using PWM (Pulse Width Modulation) control. The following results of the data obtained when the system maintains the stability of the temperature at the setpoint is $3 \mathrm{C}$. Observed data can be seen in table 4.1:
Table 4.1 Stability Testing System in Maintaining Set Point

\begin{tabular}{|l|c|c|c|c|c|}
\hline NO. & $\begin{array}{l}\text { Time } \\
\text { (minute) }\end{array}$ & & different & $\begin{array}{c}\text { error } \\
(\%)\end{array}$ \\
\hline 1 & 1 & 29.2 & 30 & 0.8 & $2.7 \%$ \\
\hline 2 & 2 & 30 & 30.5 & 0.5 & $1.6 \%$ \\
\hline 3 & 3 & 31 & 31 & 0 & $0.0 \%$ \\
\hline 4 & 4 & 31.4 & 31.5 & 0.1 & $0.3 \%$ \\
\hline 5 & 5 & 32.1 & 32.5 & 0.4 & $1.2 \%$ \\
\hline 6 & 6 & 32 & 32.5 & 0.5 & $1.5 \%$ \\
\hline 7 & 7 & 32.3 & 32.5 & 0.2 & $0.6 \%$ \\
\hline 8 & 8 & 33.3 & 33 & -0.3 & $-0.9 \%$ \\
\hline 9 & 9 & 33.4 & 33.5 & 0.1 & $0.30 \%$ \\
\hline 10 & 10 & 33.9 & 33.5 & -0.4 & $-1.2 \%$ \\
\hline 11 & 11 & 34 & 34 & 0 & $0.0 \%$ \\
\hline 12 & 12 & 34.1 & 34 & -0.1 & $-0.3 \%$ \\
\hline 13 & 13 & 34.2 & 34 & -0.2 & $-0.6 \%$ \\
\hline 14 & 14 & 34.4 & 34.5 & 0.1 & $0.3 \%$ \\
\hline 15 & 15 & 34.4 & 34.5 & 0.1 & $0.3 \%$ \\
\hline 16 & 16 & 34.4 & 34.5 & 0.1 & $0.3 \%$ \\
\hline 17 & 17 & 34.4 & 34.5 & 0.1 & $0.3 \%$ \\
\hline 18 & 18 & 34.6 & 34.5 & -0.1 & $-0.3 \%$ \\
\hline 19 & 19 & 34.6 & 34.5 & -0.1 & $-0.3 \%$ \\
\hline 20 & 20 & 34.6 & 34.5 & -0.1 & $-0.3 \%$ \\
\hline & & & & & \\
\hline
\end{tabular}

\section{CONCLUSION}

From the results of experiments conducted that the temperature differences produced by sensors and thermometers have different differences every minute, this is used as a benchmark for the accuracy of the temperature used in heating food. The regulatory system in this heater uses fuzzy logic in fan settings if the maximum temperature $31^{\circ} \mathrm{c}$ will automatically work, so the food will stay warm.

\section{ACKNOWLEDGMENT}

For further researchers, it is better to use a cast heater if using a food warmer lamp is considered ineffective but this also requires a high voltage around $220 \mathrm{~V} / 10 \mathrm{~A}$ temperature of $70{ }^{\circ} \mathrm{c}-80^{0} \mathrm{c}$

\section{REFERENCES}

[1] R., \& Rusimanto, P. W. (2019). Hidayat, "Sistem Pengendalian Temperatur Pada Inkubator Penetas Telur Otomatis Berbasis Fuzzy Logic Contro," jurnal teknik elektro, vol. 9, p. 1, Aug. 2019.

[2] H., Purwanti, D., \& Sunardiyo, S. (2017). Suryawinata, "Sistem Monitoring pada Panel Surya Menggunakan Data logger Berbasis ATmega 328 dan Real Time Clock DS1307," jurnal tenik elektro, vol. 1, p. 9, 2017.

[3] J. E. (2014). Istiyanto, Pengantar Eletronika dan Instrumentasi Pendekatan Project Arduino dan Android., Prabawati T.A, Ed. YOGYAKARTA, INDONESIA: C.V ANDI OFFSET, 2014.

[4] H., Purwanti, D., \& Sunardiyo, S. (2017). Suryawinata, "Sistem Monitoring pada Panel Surya Menggunakan Data logger Berbasis ATmega 328 dan Real Time Clock DS1307," jurnal teknik elektro, 2017. 
JAREE-Journal on Advance Research in Electrical Engineering Volume4, Number 1, April 2020

[5] A. (2015). Jenis-Jenis Microcontroller Arduino - Kelas Robot. Diambil 5 Maret 2019, dari https://kelasrobot.com/jenis-jenismicrocontroller-arduino/ Rahmat. (2019, maret) kelas robot.com. [Online]. " https://kelasrobot.com/jenis-jenis-microcontrollerarduino/"

[6] dari https://www.cronyos.com/harga-dan-spesifikasi-arduino-uno-r3/ Giri Wahyu Pambudi. (2017). Harga dan Spesifikasi Arduino Uno r3. Diambil 23 Februari 2019. (2019, februari) www.cronyos.com [Online]. "https://www.cronyos.com/harga-dan-spesifikasiarduino-uno-r3/"

[7] D. S., Pangaribuan, P., \& Surya, A. (2018). Pengendalian Suhu Air Dengan Metode Fuzzy Logic Dan Pi Kontroler. e-Proceeding of Engineering, 5(3), 4011-4018. Diambil dari https:/libraryeproceeding.telkomuniversity.ac.id/index.php/engineer ing/article Purba, "Pengendalian Suhu Air Dengan Metode Fuzzy Logic Dan Pi Kontroler," e-Proceeding of Engineering, 5(3), 40114018, vol. 5, pp. 4011-4018, Mar. 2018.

[8] \& Rusimanto, P. W. R Hidayat., "Sistem Pengendalian Temperatur Pada Inkubator Penetas Telur Otomatis Berbasis Fuzzy Logic Control. Jurnal Teknik Elektro," Jurnal Teknik Elektro, vol. 1, p. 9, Aug. 2019.

[9] D. (2013). Kho. (2013, Feb.) https://teknikelektronika.com/pengertian-relay-fungsi-relay/. [Online "https://teknikelektronika.com/pengertian-relay-fungsi relay/" 